of the sac along the inner curve of the aortic arch. DynaCT acquired non-contrast-enhanced images by rotating the digital detector of the $\mathrm{C}$-arm $360^{\circ}$ around the point of interest. The acquired images were then fused with the preoperative CT angiography to be used during live fluoroscopy. The built-in iGuide software allowed real-time access to the endoleak nidus and feeding vessels during embolization. The trajectory of the spinal needle between skin and the endoleak was accurately mapped. The needle was advanced under fluoroscopic guidance while changing the angle of the image intensifier at $90^{\circ}$ multiple times to confirm accurate positioning and prevent inadvertent graft puncture. Once inside the endoleak, direct injection of the sac was needed to confirm the absence of proximal type I endoleak.

We performed the embolization with 2 agents, glue and coils, for 2 reasons. First, the use of coils to occlude the main feeding vessel avoids accidental migration of glue to nontarget end vessels. Second, the use of glue to cast the aneurysm isolates the sac from systemic pressure and increase the success of endoleak treatment by reducing the rate of late recanalization. ${ }^{12}$

Occasionally, high radiopacity and streak artifacts of glue may interfere with detection of persistent endoleaks on follow-up CT scan. Comparison between noncontrast and contrast images can help to detect endoleak recurrence. In addition to unchanged or shrinking aneurysmal size, replacement of the embolic material at the endoleak nidus and outflow vessels can be regarded as a successful embolization.

In conclusion, this is a report of direct puncture of the aneurysmal sac for type II endoleak caused by persistent intercostal artery after hybrid repair of thoracoabdominal aneurysm. It underscores the indispensable role of the combination of fluoroscopy, DynaCT, and iGuide to make this approach safe and effective.

\section{References}

1. Zhou W, Reardon M, Peden EK, Lin PH, Lumsden AB. Hybrid approach to complex thoracic aortic aneurysms in high-risk patients: surgical challenges and clinical outcomes. J Vasc Surg. 2006;44:688-93.

2. Quinones-Baldrich W, Jimenez JC, DeRubertis B, Moore WS. Combined endovascular and surgical approach (CESA) to thoracoabdominal aortic pathology: a 10-year experience. J Vasc Surg. 2009;49:1125-34.

3. Donas KP, Czerny M, Guber I, Teufelsbauer H, Nanobachvili J. Hybrid openendovascular repair for thoracoabdominal aortic aneurysms: current status and level of evidence. Eur J Vasc Endovasc Surg. 2007;34:528-33.

4. Alsac JM, Khantalin I, Julia P, Achouh P, Farahmand P, Capdevila C, et al. The significance of endoleaks in thoracic endovascular aneurysm repair. Ann Vasc Surg. 2011;25:345-51

5. Baum RA, Stavropoulos SW, Fairman RM, Carpenter JP. Endoleaks after endovascular repair of abdominal aortic aneurysms. J Vasc Interv Radiol. 2003;14:1111-7.

6. Grabenwoger M, Fleck T, Ehrlich M, Czerny M, Hutschala D, Schoder M, et al. Secondary surgical interventions after endovascular stent-grafting of the thoracic aorta. Eur J Cardiothorac Surg. 2004;26:608-13.

7. Parmer SS, Carpenter JP, Stavropoulos SW, Fairman RM, Pochettino A, Woo EY, et al. Endoleaks after endovascular repair of thoracic aortic aneurysms. $J$ Vasc Surg. 2006;44:447-52

8. Baum RA, Carpenter JC, Golden MA, Velazquez OC, Clark TW, Stavropoulos SW, et al. Treatment of type 2 endoleaks after endovascular repair of abdominal aortic aneurysms: comparison of transarterial and translumbar techniques. J Vasc Surg. 2002;35:23-9. Erratum in: J Vasc Surg. 2002;35:852.

9. Kim JH, Yeon JE, Jong YK, Seo WK, Cha IH, Seo TS, et al. Spinal cord injury subsequent to transcatheter arterial chemoembolization in patients with hepatocellular carcinoma. Dig Liver Dis. 2010;42:67-70.

10. Stavropoulos SW, Park J, Fairman R, Carpenter J. Type 2 endoleak embolization comparison: translumbar embolization versus modified transarterial embolization. J Vasc Interv Radiol. 2009;20:1299-302.

11. Heye SJ, Vaninbroukx J, Daenens K, Maleux G. Transcatheter embolization of a type II endoleak after hybrid repair for thoracoabdominal aortic aneurysm. $J$ Vasc Interv Radiol. 2011;22:379-84.

12. Stavropoulos SW, Kim H, Clark TW, Fairman RM, Velazquez O, Carpenter JP. Embolization of type 2 endoleaks after endovascular repair of abdominal aortic aneurysms with use of cyanoacrylate with or without coils. J Vasc Interv Radiol. 2005;16:857-61.

\title{
Surgical management after stent-graft failure during the frozen elephant trunk technique for acute type A aortic dissection
}

\author{
Maximilian Luehr, MD, ${ }^{\mathrm{a}}$ Christian D. Etz, MD, PhD, ${ }^{\mathrm{a}, \mathrm{b}}$ Friedrich-Wilhelm Mohr, MD, PhD, ${ }^{\mathrm{a}}$ and \\ Michael A. Borger, MD, PhD, ${ }^{\mathrm{a}}$ Leipzig, Germany, and New York, NY
}

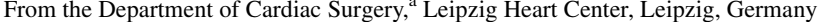
and the Department of Cardiothoracic Surgery, ${ }^{b}$ Mount Sinai School of Medicine, New York, NY

Disclosures: Authors have nothing to disclose with regard to commercial support.

Presented at The American Association for Thoracic Surgery Aortic Symposium, New York, New York, April 26-27, 2012.

Received for publication June 10, 2012; accepted for publication July 9, 2012; available ahead of print July 30, 2012

Address for reprints: Maximilian Luehr, MD, Department of Cardiac Surgery, Leipzig Heart Center, Struempellstrasse 39, 04289 Leipzig, Germany (E-mail: maximilian.luehr@med.uni-leipzig.de).

J Thorac Cardiovasc Surg 2012;144:e106-8

$0022-5223 / \$ 36.00$

Copyright (c) 2012 by The American Association for Thoracic Surgery

http://dx.doi.org/10.1016/j.jtcvs.2012.07.006
}

A 37-year-old woman was admitted to our institution on an emergency basis owing to acute type A aortic dissection with involvement of the entire thoracoabdominal aorta extending into the iliac arteries.

After cannulation of the right axillary artery, a median sternotomy was performed and cardiopulmonary bypass was subsequently initiated. The patient was cooled to a body core temperature of $25^{\circ} \mathrm{C}$ (bladder). The brachiocephalic trunk was clamped, the aortic arch was opened, and the left carotid artery was cannulated to allow for bilateral selective cerebral perfusion $\left(800 \mathrm{~mL} / \mathrm{min}\right.$ at $\left.18^{\circ} \mathrm{C}\right)$. The 


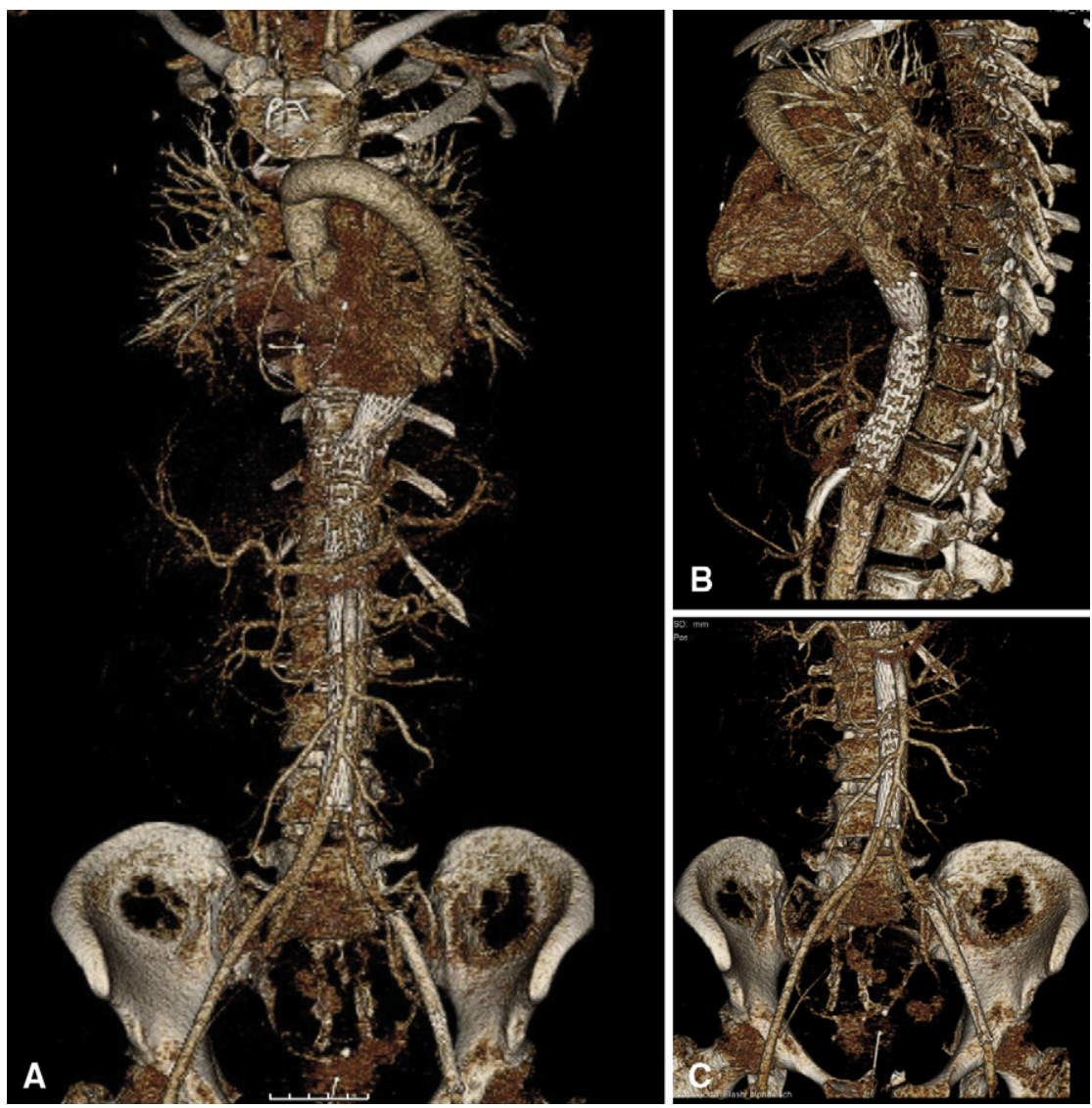

FIGURE 1. Computed tomographic scan depicts 3-dimensional reconstruction of the thoracic and thoracoabdominal aorta after extra-anatomic reconstruction and endovascular completion repair (A). Two bare metal stents and 2 covered stents were deployed in the thoracoabdominal aorta and the superior mesenteric artery, respectively. The celiac trunk and the superior mesenteric artery are sufficiently perfused (B). Two covered stents were deployed in the left external iliac artery $(C)$.

left subclavian artery was occluded with a Fogarty catheter. An entry site in the transverse aortic arch and a reentry site in the proximal descending aorta (DA) were observed, necessitating complete aortic arch replacement. The coronary sinuses and the supra-aortic branches were spared from dissection, allowing for supracoronary replacement of the ascending aorta and aortic arch reconstruction via the island technique.

To exclude the reentry site, we used a guidewire to insert a hybrid stent-graft prosthesis (E-vita size $24 \mathrm{~mm}$; Jotec $\mathrm{GmbH}$, Hechingen, Germany) into the narrow true lumen of the dissected DA. No oversizing was performed. After antegrade stent-graft deployment, the graft portion was trapped in the depth of the DA and could not be successfully withdrawn.

It was therefore decided to remove the hybrid device and to perform a conventional elephant trunk procedure with a Hemashield prosthesis (Maquet, San Jose, Calif). However, removal of the deployed stent graft resulted in extensive laceration and extirpation of the intima and media of the entire proximal DA. Only the adventitia remained intact, and it was immediately oversewn to prevent back bleeding from the intercostal arteries.

A Hemashield prosthesis $(24 \mathrm{~mm})$ was anastomosed end to end to the prepared island of aortic tissue including the supra-aortic vessels. After fenestration of the posterior pericardium, a 20-mm Hemashield graft was anastomosed end to end to the distal DA at the level of T10. The proximal DA stump was oversewn at this level and the Hemashield graft was tunnelled through the pericardium, around the left atrial appendage and pulmonary artery, and then anastomosed end to side with the proximal 24-mm Hemashield graft. Full systemic perfusion with rewarming was instituted after 91 minutes of distal circulatory arrest and selective cerebral perfusion. Finally, the proximal end of the 24-mm Hemashield graft was anastomosed to the sinotubular junction.

The patient was transferred to our intensive care unit with stable hemodynamics. An early postoperative computed tomographic angiogram was performed because of a cold left leg and rising lactate level. The computed tomographic angiogram revealed persisting dissection of the thoracoabdominal aorta with a very narrow true lumen and 
malperfusion of the celiac trunk, superior mesenteric artery, renal arteries, and left external iliac artery.

Emergency endovascular stent grafting was performed 6 hours after the initial operation. Two aortic selfexpendable, noncovered stents $(\mathrm{E}-\mathrm{XL}, 32 \mathrm{~mm} \times 130$ $\mathrm{mm}$ and $28 \mathrm{~mm} \times 100 \mathrm{~mm}$; Jotec $\mathrm{GmbH}$ ) were placed in the dissected thoracoabdominal aorta to expand the true lumen and increase perfusion of the abdominal branches. Persistent superior mesenteric artery malperfusion was treated with 2 balloon-expandable Herculink stents $(6.5 \mathrm{~mm} \times 18 \mathrm{~mm}$; Guidant, Indianapolis, Ind), and 2 self-expandable nitinol SMART iliac stents (8 $\mathrm{mm} \times 60 \mathrm{~mm}$ and $7 \mathrm{~mm} \times 40 \mathrm{~mm}$; Cordis Corperation, Bridgewater, NJ) were deployed into the left external iliac artery. Postprocedure angiography showed sufficient perfusion of all abdominal aortic branches and the arteries of the left leg (Figure 1).

The patient was successfully weaned from the ventilator 8 weeks postoperatively after a prolonged clinical course. Eleven weeks after the initial operation, she was mobilizing fully without any permanent neurologic deficits.

\section{DISCUSSION}

The frozen elephant trunk technique allows for singlestage repair of the ascending aorta and transverse aortic arch after antegrade endovascular treatment of the DA. ${ }^{1,2}$ In patients with acute type A dissection, coverage of additional intimal tears and improved true lumen perfusion may lead to false lumen exclusion and obliteration after the frozen elephant trunk procedure. ${ }^{3} \mathrm{Al}-$ though midterm results for this technique are promising, controversy exists as to whether a hybrid or a conventional approach should be applied for type A aortic dissection. . $^{3,4}$

The case described herein reveals an unexpected intraoperative complication requiring switching from a hybrid to a conventional surgical repair with extra-anatomic reconstruction of the thoracic aorta, followed by emergency endovascular treatment of the remaining aorta owing to significant malperfusion. Our case illustrates the complex and multidisciplinary approach that is occasionally required for patients with acute aortic dissection.

The precise cause of the technical device failure during our frozen elephant trunk operation is difficult to determine. We can postulate, however, that stent-graft deployment in the very small true lumen might have resulted in trapping of the device's nose cone and inability to extract the prosthetic portion of the hybrid device. A newer version of the E-vita stent graft (E-vita open plus; Jotec $\mathrm{GmbH}$ ) now has a much lower profile nose cone to prevent this problem from occurring.

\section{References}

1. Karck M, Chavan A, Hagl C, Friedrich H, Galanski M, Haverich A. The frozen elephant trunk technique: a new treatment for thoracic aortic aneurysms. J Thorac Cardiovasc Surg. 2003;125:1550-3.

2. Tsagakis K, Pacini D, Di Bartolomeo R, Benedik J, Cerny S, Gorlitzer M, et al. Arch replacement and downstream stent grafting in complex aortic dissection: first results of an international registry. Eur J Cardiothorac Surg. 2011;39:87-93; discussion 93-4.

3. Uchida N, Ishihara H, Shibamura H, Kyo Y, Ozawa M. Midterm results of extensive primary repair of the thoracic aorta by means of total arch replacement with open stent graft placement for an acute type A aortic dissection. J Thorac Cardiovasc Surg. 2006;131:862-7.

4. Dobrilovic N, Elefteriades JA. Stenting the descending aorta during repair of type A dissection: technology looking for an application? J Thorac Cardiovasc Surg. 2006;131:777-8.

\title{
Long-term systemic right ventricular support in transposition and dextrocardia
}

\author{
Aekarach Ariyachaipanich, MD, ${ }^{\mathrm{a}}$ James O. Mudd, MD, ${ }^{\mathrm{a}}$ Jill Gelow, MD, ${ }^{\text {a }}$ and Howard K. Song, MD, PhD, ${ }^{\mathrm{b}}$ \\ Portland, Oregon
}

\footnotetext{
From the Divisions of Cardiovascular Medicine ${ }^{\mathrm{a}}$ and Cardiothoracic Surgery, Oregon Health \& Science University, Portland, Ore.

Disclosures: Authors have nothing to disclose with regard to commercial support.

Received for publication April 19, 2012; revisions received June 8, 2012; accepted for publication July 10, 2012; available ahead of print Aug 6, 2012.

Address for reprints: Aekarach Ariyachaipanich, MD, Oregon Health \& Science University, Mail Code UHN-62, 3181 SW Sam Jackson Park Rd, Portland, OR 97239 (E-mail: ariyacha@ohsu.edu).

J Thorac Cardiovasc Surg 2012;144:e108-10

$0022-5223 / \$ 36.00$

Copyright (C) 2012 by The American Association for Thoracic Surgery

http://dx.doi.org/10.1016/j.jtcvs.2012.07.017
}

For patients with complex congenital heart disease (CHD) who are in end-stage heart failure, a significant disparity in the use of mechanical circulatory support persists. ${ }^{1}$ Recent reports have shown the feasibility and initial success of supporting patients with systemic morphologic right ventricles (RVs) with continuous-flow ventricular assist devices (VADs) ${ }^{2}$; however, long-term outcome data are lacking. We present our successful experience with a HeartMate II left ventricular assist system (Thoratec Corporation; Pleasanton, Calif) in a mirror image position to support the 